\title{
Responsabilidade pelo que Percebemos: Fundamentos de Reology, de Jake Eagle
}

\author{
Responsibility for What We Perceive: \\ Fundamentals of Reology, by Jake Eagle
}

\author{
Cláudia Maria Moura Pierre ${ }^{I}$
}

\begin{abstract}
"No matter what you tell me about, you're telling me about your experience and your perception. Everything 'out there', by the time it travels through your filters, becomes a part of you, your version of what's out there" (TOM, in EAGLE, 2011, p. 48)

Não importa o que você me relata, você está me relatando sobre sua experiência e sua percepção. Tudo 'lá fora', ao atravessar seus filtros, se torna uma parte de você, sua versão sobre o que acontece 'lá fora".
\end{abstract}

Este artigo é resultado da leitura do livro ReRight Your Life: an introduction to Reology, de Jake Eagle, e do workshop que participei, em 2014. São apresentados os fundamentos de Reology, que consiste numa filosofia e num modo de viver que promove total responsabilidade de cada um por sua vida, e desta forma ameniza o sofrimento e elimina o vitimismo.

Também podemos pensar em Reology como uma abordagem terapêutica a fim de que tenhamos uma vida mais alegre e saudável. Reology ensina uma nova maneira de se comunicar, modificando a linguagem. Isto ocorre de uma maneira que fica explícito que o mundo que estamos está falando é o mundo que nós percebemos. E, nesta nova maneira de se comunicar, assumimos responsabilidade pelo que estamos vendo e sentindo. Para Eagle, a forma que conversamos - conosco e com outras pessoas -determina a qualidade de nossos relacionamentos. ('The way we talk to ourselves and other people determines the quality of our relationships'. EAGLE, 2011, p. 19).

Jake Eagle é psicoterapeuta que, juntamente com sua esposa, Hannah - conduz retiros em todo o mundo nos quais há uma profunda reflexão sobre os sentimentos e valores de cada participante. Através de seus ensinamentos, as pessoas são levadas a reorientar suas vidas com o intuito de se relacionar melhor com os outros e com eventos, na medida em que conhecem mais sobre si mesmas, assumindo 'radical responsibility' (responsabilidade radical) por suas vidas.

\footnotetext{
${ }^{1}$ Cientista Social com Mestrado em Sociologia e Doutoranda em Educação. Professora Adjunta da Universidade Regional do Cariri.
} 
Em seu livro, já no primeiro parágrafo da Introdução, Jake Eagle afirma que está oferecendo um presente, que demonstra um 'modo de viver, uma prática real que fomenta uma existência pacífica'. (I want to offer you a gift. The gift is a way of living, an actual practice that fosters peaceful coexistence (p. 2).

Este presente fomenta a paz porque, em sua essência, está a ideia de que o mundo que vivemos é o mundo que percebemos e a percepção acontece através de filtros pessoais em que toda uma gama de idiossincrasias tem lugar. O modo como percebemos 'a realidade' é subjetivo. O que entra em consideração quando percebemos o que percebemos é influenciado por fatores como família, cultura, origem étnica, educação, religião, capacidades pessoais, crenças, necessidades, valores etc. É o que ele denomina 'percept screen'. Todos temos uma tela perceptiva através do qual concebemos a realidade.

Assim se expressa Eagle: 'todos os estímulos são editados e alterados por estes filtres e este processo cria nossa consciência individual'. 'All income stimuli are edited and altered by these filters and this process creates our individual consciousness' (p.25). E ainda " cada um de nós experimenta os estímulos externos de uma maneira única." Each of us experiences these external stimuli in a unique way" (p. 25)

A pedra de toque repousa na questão da percepção. Dado que o que percebemos passa por uma tela perceptiva subjetiva, isto significa que vemos através de nossos valores, medos, desejos e nossas memórias. O modo de ver o mundo é pessoal, vemos através de nossa tela perceptiva, vemos a partir de nós, do modo como somos feitos, de nossos valores e das experiências que formataram nosso ser.

Isto significa também que, na verdade, nós encontramos o reflexo (de nós mesmos) em tudo e cada pessoa que encontramos ('We find our reflections in everything and every person we encounter ' (p.4): É consequência obrigatória, portanto, assumir responsabilidade pelo que vemos. Poderia afirmar, lembrando 'A Course in Miracles' que 'a projeção faz a percepção' (p.520).

Jake Eagle coloca que nós re-apresentamos o mundo para nós mesmos - momento a momento ( 'we re-present the world to ourselves - moment by moment ( p.19). Isto toca na indagação do que vem a ser a realidade e tem implicações profundas em nossa maneira de ser e estar no mundo. A implicação principal que ele trabalha em todo o livro é que devemos assumir total responsabilidade pelo que vemos e pelo que sentimos. É esta a chave para viver uma vida mais plena e melhorar os relacionamentos.

Esta mudança de percepção leva a uma mudança no modo como nos relacionamos com os demais, com a vida. De acordo com esta perspectiva, deixamos de culpar os outros - o que é causa do vitimismo e dos conflitos nos relacionamentos. Na condição de adultos nós nos tornamos totalmente 
responsáveis em como nos comportamos ( 'we become fully responsible for how we conduct ourselves' p.3).

Considerando o fundamento deste modo de conceber como configuramos a realidade, há um corolário importante a ser considerado - não existe certo ou errado - existe apenas o modo como percebemos os eventos - que pode ser bem diferente do modo como o outro percebe os mesmos eventos. Esta visão nos leva a abandonar a necessidade de estarmos certos, que é a origem do desejo de culpamos os outros.

Para Jake Eagle, um modo de viver que compreenda estas considerações está profundamente enraizado em nosso natural desejo de desenvolvimento, por isto, trata-se de algo revigorante. Ele afirma que nós temos que encarar alguns desafios: deixar de resistir às incertezas, deixar de negar a impermanência, tentar estar no presente momento, deixar de defender nossa identidade e assumir total responsabilidade por nós.

Um dos grandes problemas que enfrentamos é causado por distorções que temos sobre quem somos nós e por distorções geradas no passado e que ainda carregamos conosco. Muitas vezes, trazemos comportamentos da infância e queremos que o mundo funcione ainda de acordo com os padrões erigidos nesta época de nossa vida. E, aprendi que, em se tratando de trauma, vemos o mundo de acordo com nossa percepção distorcida pelo trauma.

Jake afirma que, se a noção que temos sobre nós é distorcida, é muito difícil responder apropriadamente às situações. É nossa maturidade emocional que vai determinar que respostas são apropriadas a cada situação dada. Comportamentos distorcidos se manifestam quando nos sentimos vitimizados pelas pessoas. Responder apropriadamente significa que respondemos ao que está acontecendo agora, não no passado.

Uma das maneiras de ficarmos no presente consiste em usar a linguagem ReSpeak. Ela batizou de ReSpeak a uma nova maneira de falar em que assumimos nossos sentimentos. Quando nos expressamos, não dizemos que estamos com raiva por causa de algo externo a nós, mas nos apropriamos da raiva como algo que é nosso.

Este modo de falar compreende duas diretrizes: a primeira é 'resource our feelings' - o que significa considerar a fonte de nossos sentimentos. De acordo com a filosofia que fundamenta ReSpeak, a fonte de nossos sentimentos se encontra em nosso próprio ser. Deste modo, assumimos que nosso modo de sentir e a forma como o mundo se apresenta para nós depende de nós. Eagle escreve: "I own my feelings and inner experiences..." own significa possuir, tornar nosso. Isto que dizer, então: eu me apodero, eu tomo posse de meus sentimentos, de minhas experiências internas.

No ReSpeak substituímos a injunção 'você me causou frustração', por 'eu frustrei a mim mesmo', mudamos o sentido do que vivemos. Ao reconhecermos a fonte do sentimento como nossa , mudamos a forma como vivemos a experiência. Há uma mudança do sentimento na forma de 
substantivo para verbo. Quando transformamos os substantivos em verbos, geramos um estado dinâmico ao invés de estático: I am depressed - estou com depressão; I depress myself - eu me deprimi, eu produzi esta depressão em mim...). Deste modo, consideramos que estamos em determinado estado emocional, neste momento presente.

Considerando que recriamos o mundo externo a partir do mundo interno (re-creating the world 'out there' within ourselves. p.19), podemos intervir a qualquer momento e fazer escolhas. Nas palavras do psicoterapeuta: temos escolhas em como respondemos às pessoas e ao mundo ( 'we have a choice in how we respond to people and to the world' (p.20).

Nós podemos viver de acordo com padrões do passado, ficar ligados às feridas da infância ou nos liberar desses padrões à medida que tomamos consciência que somos nós que interpretamos o mundo. Temos escolhas, podemos refazer nosso ser (we can Re-do ourselves).

O autor menciona a frase atribuída a Audous Huxley que serve de base para todo o desenvolvimento de seu raciocínio: experiência não é o que acontece com você; é o que você faz com o que acontece a você" ('experience is not what happens to you; it's what you do with what happens to you' (p.20). Somos nós que atribuímos significado ao que acontece a nós. Para um mesmo evento cada um atribui um significado diferente. Por isto, J. Eagle afirma que nós somos responsáveis pela maneira que respondemos com o que acontece a nós.

Partindo desta premissa, Eagle propõe o que ele denomina de Reology . Reology consiste numa reorientação radical sobre como nos colocamos diante do mundo, trata-se de um novo modo de perceber e, portanto, de se conduzir na vida. Reology é uma mudança de paradigma (paradigm shift). Assim se expressa Jake: 'This is what Reology/ReSpeak has been for me, a new way to see myself and the way I create my life' (8/2 \#14). Este novo paradigma sobre como percebemos, nos leva a uma maior consciência de nós, nos conecta mais com nossos sentimentos.

Se somos responsáveis pelo modo como sentimos, não somos vítimas do mundo. Esta postura é revolucionária, eu diria. E, se não somos vítimas do mundo, o sofrimento é amenizado, pois uma das grandes causas do sofrimento é o conflito, ao considerarmos a nós como vítimas, entramos em conflito com o outro, pois atribuímos a ele a causa de nosso sofrimento.

O título do capítulo II de seu livro é: quem é o arquiteto de sua vida? Para ele a resposta é clara. O ponto central é enfatizado mais uma vez - somos arquitetos de nosso própria vida. Se cada um de nós atribui significado a tudo que acontece em nossa vida, não existe uma realidade fora de nós. Nossa percepção muda de foco: do mundo externo para interno - para nosso próprio ser, nossos valores, nossos sentimentos.

A realidade passa a ser compreendida como um resultado do significado que atribuímos ao que vivemos. E, se configuramos nossa própria realidade, damo-nos conta de que não respondemos ao mundo, respondemos ao modo como erigimos o significado do mundo (p.24). Paramos de achar que as 
pessoas fazem 'coisas' a nós. Somos nós que fazemos o que fazemos a partir do que acontece a nós. Isto necessariamente nos leva a uma postura diferente diante das pessoas e dos acontecimentos.

Há um reconhecimento de que não há uma realidade intrínseca, ou objetiva. Isto fundamenta a nova linguagem (ReSpeak) e nos leva a mudar a postura diante do que consideramos um ataque. Quando alguém nos insulta ou nos acusa, ao invés de nos sentirmos melindrados, ou contra-atacar, assumimos uma postura de curiosidade: porque a pessoa está dizendo isto, porque está agindo assim?

A postura de curiosidade substitui a postura de vitimismo, de defensividade e de ataque. Esta consideração sobre a percepção/realidade leva a uma total mudança de perspectiva que fomenta relacionamentos mais pacíficos em contraste com o sofrimento inerente ao conflito.

\section{Referências}

BARNES e NOBLE. A Course in Miracles. A Course in Miracles International, 2007.

EAGLE, Jake. ReRight Your Life: an introduction to Reology. Novo México. Publicação independente. 2011

\section{Como citar este artigo (Formato ISO):}

PIERRE, C.M.M.. Responsabilidade pelo que percebemos: Fundamentos de Reology, de Jake Eagle. Id on Line Revista de Psicologia, Fevereiro de 2014, vol.8, n.22, p. 18-22. ISSN 1981-1189. 